\title{
About solvents used in the preparation of oils for cosmetic products complying with the Cosmos standard ${ }^{\text {th }}$
}

\author{
Patrick Carré* \\ Iterg, 11, rue Gaspard Monge, 33600 Pessac, France
}

Received 26 November 2020

\begin{abstract}
Solvents have a bad reputation in the cosmetics world, at least as regards the production of specialty vegetable oils used in this market. In order to do without these solvents, the cosmetics industry tends to use only mechanically produced oils. However, there is a range of seeds for which mechanical extraction is not satisfactory. This is the case with rare, expensive, and oil-poor seeds for which pressing does not give good yields, and results in high production costs. These are also hard seeds that cannot be pressed without causing the presses to become intensely hot, and this affects the quality of the oils. In recent years, our laboratory has worked on the development of extraction techniques with ethanol and the EcoXtract $^{(\mathbb{R}}$ solvent (2-methyloxolane) in order to provide professionals with production methods compatible with the COSMOS standard. Ethanol is not a good solvent for oils, especially in the presence of water and at low temperature. This drawback can be turned into an advantage to recover the oil (without distillation of the solvent) by cold decantation. The extraction is carried out on the hot components, and the oil is recovered by cooling the saturated miscella for the precipitation of the lipid phase. This process makes it possible to limit the energy consumption necessary for the recovery of the oil and the regeneration of the solvent. The great advantage for oils intended for the cosmetic market is that ethanol has a better solvent power for polar lipids compared to hexane and mechanical extraction. It is possible to split the lipid extract into neutral lipids and polar lipids by adjusting the precipitation temperature or by partial distillation. At the refining step, it is also possible to deacidify and remove contaminants from crude oil by liquid-liquid extraction with ethanol. We have recently obtained interesting results by reducing the phthalate concentration of walnut oils by $90 \%$. The use of ethanol for oil neutralization is a process which generates less loss of neutral oil than the alkaline neutralization of a mixture with high acidity, and this is less harmful than physical refining during the production of 3-MCPD esters, esters of glycidol, and trans fatty acids. EcoXtract ${ }^{\circledR}$ is a solvent derived from the chemistry of pentoses in biomass. This solvent has very good oil solvation capacities and less biological toxicity than hexane. Its production has an acceptable carbon footprint and good sustainability characteristics. It is recognised by Ecocert as suitable for producing COSMOS ingredients. Compared to ethanol, its use requires fewer preparation steps (ethanol requires rigorous drying before extraction) and it requires less circulating solvent per kilo of oil extracted. The solvent removal from the meal requires less energy and allows the use of direct steam to aid in the removal of the solvent since the miscibility of water in this solvent is limited to $4.5 \mathrm{~g} / 100 \mathrm{~g}$.
\end{abstract}

Keywords: solvents / cosmetics / process / ethanol / EcoXtract ${ }^{\circledR}$

Résumé - À propos de l'usage des solvants pour la préparation d'huiles végétales destinées aux produits cosmétiques sous référentiel COSMOS. Les solvants ont une mauvaise réputation dans le monde des cosmétiques, du moins en ce qui concerne la production d'huiles végétales de spécialité. Pour se passer de ces solvants, l'industrie cosmétique a tendance à n'utiliser que des huiles produites mécaniquement. Il existe néanmoins une gamme de graines pour lesquelles l'extraction mécanique n'est pas satisfaisante. C'est le cas de graines rares, chères et pauvres en huile pour lesquelles le pressage ne donne pas de bons rendements, et aboutit à des coûts de production élevés. Il peut également s'agir de

\footnotetext{
is Contribution to the Topical Issue "Lipids and Cosmetics / Lipides et cosmétiques".

*Correspondence: p.carre@iterg.com
} 
graines dures qui ne peuvent être pressées sans provoquer un échauffement intense dans les presses qui affecte la qualité des huiles. Notre laboratoire a travaillé ces dernières années au développement de techniques d'extraction à l'éthanol et au solvant EcoXtract ${ }^{\mathbb{B}}$ (2-méthyloxolane) afin de fournir aux professionnels des méthodes de production compatibles avec le référentiel COSMOS. L'éthanol n'est pas un bon solvant des huiles, surtout en présence d'eau à basse température. Cet inconvénient peut être tourné en avantage afin de récupérer l'huile sans distillation du solvant par décantation à froid. L'extraction se fait à chaud et la récupération de l'huile par refroidissement du miscella saturé pour précipiter de la phase lipidique. Ce procédé permet de limiter la consommation d'énergie nécessaire à la récupération de l'huile et à la régénération du solvant. Le grand avantage pour l'huile destinée au marché des cosmétiques est que l'éthanol a un meilleur pouvoir solvant pour les lipides polaires par rapport à l'hexane et à l'extraction mécanique. Il est possible de fractionner l'extrait lipidique en lipides neutres et lipides polaires en jouant sur la température de précipitation ou par distillation partielle. Au stade du raffinage, il est également possible de désacidifier et d'éliminer les contaminants de l'huile brute par extraction liquide-liquide avec de l'éthanol. Nous avons récemment obtenu des résultats intéressants en réduisant la concentration en phtalates des huiles de noix de $90 \%$. L'utilisation de l'éthanol pour la neutralisation des huiles est un procédé qui génère moins de pertes d'huile neutre que la neutralisation alcaline et qui est moins nocif que le raffinage physique en ce qui concerne la production d'esters de 3-MCPD, d'esters de glycidol et d'acides gras trans. EcoXtract ${ }^{\mathbb{B}}$ est un solvant issu de la chimie des pentoses provenant de biomasse. Ce solvant a de très bonnes capacités de solvatation des huiles et une toxicité biologique moindre que celle de l'hexane. Sa production a une empreinte carbone acceptable et de bonnes caractéristiques de durabilité. Il est reconnu par Ecocert comme adapté à la production d'ingrédients COSMOS. Par rapport à l'éthanol, son utilisation nécessite moins d'étapes de préparation (l'éthanol exige un séchage rigoureux avant l'extraction) et nécessite moins de solvant circulant par kilo d'huile extraite. La désolvantation des tourteaux requiers moins d'énergie et autorise l'usage de vapeur directe pour aider à l'élimination du solvant car la miscibilité de l'eau dans ce solvant est limitée à $4.5 \mathrm{~g} / 100 \mathrm{~g}$.

Mots clés : solvants / cosmétiques / procédés / éthanol / EcoXtract ${ }^{\circledR}$

\section{Introduction}

In the world of cosmetics, solvents have a public acceptability problem because they are associated with carcinogenic chlorinated solvents or with petroleum cuts of ill-defined composition which may also contain toxic molecules. Solvents are, at any rate, not anti-natural, and life could not be possible without the ubiquitous solvent known as water. The dogmatic rejection of solvents is not part of the COSMOS standard (COSMOS, 2020) which provides guiding rules for the preparation of cosmetics ingredients based on "organic" material. This allows their use with certain precautions when the physical methods are insufficient to achieve the desired quality. The only clearly stated prohibition concerns petroleum-based solvents. As part of the processing of vegetable oils, the conditions to be met for the use of solvents are as follows:

- The solvent must come from renewable materials,

- Its manufacture must comply with the green chemistry charter,

- No product derived from GMOs must have been used to ensure its production

- The solvent must not be toxic,

- No residue should be found in the oil,

- It must not harm the health of the workers who use it.

\subsection{Regarding the limits of mechanical extraction}

Mechanical extraction of vegetable oils is the preferred physical process for so-called "organic" oils because this process enables simple and relatively efficient extraction.
More often, suppliers try to obtain oils by cold pressing to preserve the organoleptic quality of the oils, which in oils for cosmetic purposes means reducing odour uptake and preserving a relatively light colour (Matthäus and Spener, 2008). In general, this solution is satisfactory and provides access to a very wide range of good quality lipids as it is the case for argan oil (Matthäus, 2013).

However, this solution has several disadvantages which penalise certain specialty oils. The first of these limitations concerns the extraction yields of seeds with low oil content. Some important sources for cosmetics - such as Rosa mosqueta oil - are seeds with an oil content not exceeding $10 \%$. In this case, it is difficult to obtain high extraction yields because screw presses rarely produce cakes with less than 5-6\% oil (Savoire et al., 2013). Take the case of the rosehip, the seeds of which can be worth up to $2.5 € / \mathrm{kg}$ and contain only $7 \%$ oil. Assuming that cold pressing yields $4 \mathrm{~kg}$ of oil per $100 \mathrm{~kg}$ of seeds - which is a rather optimistic yield (Topkafa (2016) reports a yield of 3.1\% using an Ecotok press) - it takes $62.5 €$ of seeds to produce $1 \mathrm{~kg}$ of oil. When processing the same seeds using solvent extraction, we could obtain around $6.8 \mathrm{~kg}$ of oil for $100 \mathrm{~kg}$ of seeds at the OLEAD extraction plant with a continuous counterflow extractor. That yield reduces the cost of seeds per unit mass of oil to $36.8 € / \mathrm{kg}$. By adding to the cost of the seeds that of an extraction process evaluated at $500 € / t$ of crushed seeds, we can estimate that the cost of virgin oil would be $75 €$ per kilogram (if virgin oil cost $=\operatorname{cost}$ of the seeds + cost of the processing). As an assumption, we can therefore estimate that virgin oil cannot be worth less than $75 € / \mathrm{kg}$. Oil from solvent extraction will probably be discounted in comparison to virgin oil; if we apply a discount of $10 \%$, the resulting estimated cost will be $67.5 € / \mathrm{kg}$. 
As a result, by producing virgin oil with one ton of seed, we can produce $40 \mathrm{~kg}$ of oil with a total value of $3000 €$ while with solvent extraction, we would produce $68 \mathrm{~kg}$ of oil with a total value of $4590 €$ : the purchasing cost of the seed is $2500 € / t$, and the extraction and refining process $2090 € / \mathrm{t}$, with refining being made necessary for complete elimination of the solvent. According to our experience acquired within the CREOL then OLEAD $^{1}$ unit, this amount may be realistic in the context of a unit working with a green solvent on a small scale $(<400 \mathrm{~kg} / \mathrm{h}$ of seeds) provided that we are able to operate this unit for a sufficient period of time throughout the year.

\subsection{Benefits of solvent extraction}

The ability of solvent extraction to better extract lipids is a factor in reducing ecological impacts when the raw material comes from endemic wild species because it requires less consumption of raw material for the same amount of oil produced. It also has the benefit of an improved extraction of polar lipids like phospholipids, glycolipids, monoacylglycerol, which are of great interest in cosmetic products (Ghazani et al., 2014). Cold pressed oils are generally free of phospholipids due to the method of extraction. As a result, they are less rich in minor compounds like tocopherols and phytosterols which are partly linked to the cell membranes where the phospholipids are located (Prior et al., 1991).

Finally, in the case of matrices poor in oil and rich in lignified fibers (rosehip, passion fruit, grape, prickly pear seeds for example), it is impossible to obtain good yields of oil without a significant increase in the temperature during pressing. Venkitasamy et al. (2014), for example, obtained the best oil yields on grapeseed in a Komet press at temperatures between 130 and $140{ }^{\circ} \mathrm{C}$. This increase in temperature can result in a loss of quality since high temperature promotes colour darkening, oxidation and degradation of antioxidant molecules (Choe and Min, 2006). In comparing the sensory quality of dehulled and undehulled sunflower cold pressed oils, Raß et al. (2008) found that dehulling improved the sensory quality, eliminating a bitter and woody taste that would otherwise be present. With oils that are very sensitive to oxidation such as flaxseed, pomegranate, chia, etc., high temperature can promote the oxidation of lipids. Thus, contrary to popular belief, a solvent extraction can often result in oils that are more interesting from the point of view of richness in micronutrients and oxidative stability.

\section{Ethanol as an extraction solvent}

Starting in 1927, ethanol was first employed as an extraction solvent in its first semi-industrial application in Manchuria, when the Central Laboratory of the South Manchuria Railway Company commissioned a project to extract soya oil with ethanol (Hron et al., 1982).

\footnotetext{
1 CREOL was a small commercial company running a pilot plant dedicated to the processing of oilseeds. It became OLEAD in 2016 when ITERG brought its refining plant to it. The solvent extraction plant is currently at a standstill but will resume service next year as part of a new venture.
}

The disadvantages of using ethanol for lipid extraction are: - This solvent is completely miscible with water, unlike hexane, which is used for conventional oils. It is therefore likely to become mixed with water on contact with plant material.

- The oil is poorly soluble in this solvent and its solubility depends on both the water content of the solvent and its temperature. For example, Rao et al. (1955) found that crude soybean oil maximum solubility at $40^{\circ} \mathrm{C}$ in ethanol with $0 \%, 4.5 \%$ and $8.5 \%$ of water was $10.6,4.2$ and $2.4 \mathrm{~g} / 100 \mathrm{~g}$ and at $60^{\circ} \mathrm{C}$ : 27.0, 7.5 and $4.2 \mathrm{~g} / 100 \mathrm{~g}$ respectively. Consequently, with a solvent close to the azeotropic concentration, more solvent is required to dissolve the oil to be extracted than in the case of hexane.

- It forms an azeotrope with water which makes it difficult to obtain a $100 \%$ pure solvent during distillation. Moreover, the distillation in the presence of water is much more energy-intensive than the simple evaporation of hexane. This relates more particularly to the desolventization of the meal. In the case of hexane, it is possible to use direct steam to completely remove the solvent residues from the cake, but in the case of ethanol, this water vapor will mix with the solvent and require a distillation step with a large reflux of condensates to reach the azeotrope concentration. It is therefore necessary to employ rectification columns, which represent sizable capital costs and energy consumption. To avoid introducing water into the system, it is necessary to dry the oil-bearing material to less than $3 \%$ water, and this adds a significant energy cost (Hron et al., 1982).

However, these disadvantages are outweighed by many advantages:

- Ethanol is a solvent produced by renewable biological processes,

- The solvent has all the required authorizations and is available at low cost.

- This solvent is often used in cosmetic products and the presence of residues in this case does not raise the same concerns as for residues of solvents such as hexane.

- Its vapors are considered to be much less harmful to workers than hexane vapors.

- The separation between oil and solvent does not require evaporating all of the miscella. The low oil/ethanol miscibility can be used to precipitate oil from miscella by reducing its temperature. This produces a heavy phase with more than $90 \%$ oil and a so-called "lean" miscella phase with less than 1-2\% oil (Beckel et al., 1948). This lean miscella can undergo another extraction procedure involving a membrane separation step to recover the polar lipids it contains.

- Ethanol extracts polar lipids and minor compounds that are of interest in cosmetics (glycolipids, phospholipids, phytosterols, tocopherols, phenolic, ...) much better than hexane does (Moreau et al., 2003).

- Ethanol makes it possible to extract non-lipidic compounds, especially phenolic compounds which may be of interest for cosmetic applications and also to reduce the colour and bad taste of delipidated flours (Johnson and Lusas, 1983; Kuk and Hron, 1998). 


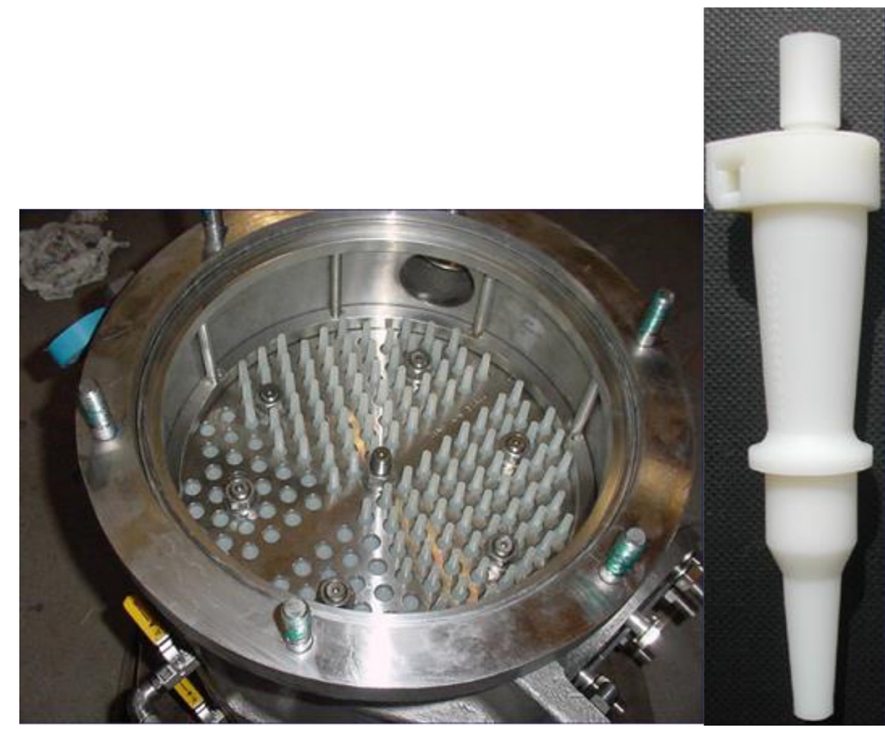

Fig. 1. Cyclonette (right) and plate device grouping many cyclonettes for industrial solid/liquid separation (courtesy of Alfa-Laval).

The first large-scale study ${ }^{2}$ that we carried out on the use of ethanol as an extraction solvent is a study which aimed to test a process proposed by the company Alfa-Laval based on a solidliquid separation by means of hydrocyclones. The original idea was to compensate for the low solubility of the oil in the solvent by working at temperatures above the boiling point of the solvent. This is not possible in conventional extractors which all operate by percolating liquid under atmospheric pressure. For this, Alfa-Laval proposes to reduce the matrix (that will undergo extraction) to the form of a fine powder (50$200 \mu \mathrm{m})$ so as to form a suspension, the separation of which would be achieved in small cyclonettes arranged in large numbers in devices such as the one in Figure 1. The advantage of this device, besides requiring less solvent, is to accelerate the diffusion of oil. Indeed, the diffusion is linked by an exponential relation to the size of the particles according to the equation (1).

$$
E=1-e^{\left(-D_{\text {eff }} \frac{\pi^{2}}{r^{2}} \cdot t\right)},
$$

- E: extraction rate (oil extracted/extractable oil) (\%);

- Deff: Diffusivity coefficient $\left(\mathrm{m}^{2} \mathrm{~s}^{-1}\right)$;

- r: Particles radius $(\mathrm{m})$;

$-\mathrm{t}$ : time (s).

In consequence, it becomes possible to run the unit at high capacity with equipment of limited scale, and to restrict the time that proteins and ethanol are in contact, thereby lessening the impact on their solubility. The $D_{\text {eff }}$ values depend on the matrix and on the extraction conditions, including temperature. In the best scenario, contact times of less than 2 minutes are sufficient to extract $95 \%$ of the oil contained the solid particles

\footnotetext{
${ }^{2}$ PROVEGAL project funded by the French Agency for the Research ANR13-ALID-0003-01.
}

of less than $100 \mu \mathrm{m}$ in comparison to nearly 20 minutes for conventional flakes of material.

A cascade of cyclonettes, would facilitate a countercurrent extraction according to the diagram in Figure 2. The figure shows the presence of two clarification stages and the presence of a horizontal centrifuge decanter. These devices are made necessary by an imperfect quality of separation of the hydrocyclones which decompose the suspension between an overflow still containing 2 to $10 \%$ of particles and an underflow which must remain sufficiently rich in liquid to make it possible not to clog the cyclonettes with too much solid. The clarification cyclonettes thus serve to eliminate the residual particles to a level close to zero in the miscella, which itself must then be cooled and decanted for oil recovery. At the other end of the line, the centrifuge decanter has to dry the spent solid which then proceeds to the desolventizer, holding the least possible amount of liquid to limit the energy required to remove it.

Upstream of this installation, there must be a drying unit to remove unwanted water in the system as indicated above and a grinding unit in the solvent whose function is to reduce the material to the desired particle size. Heat exchanger systems are required at the inlet and outlet of the flows to limit the heat flow: the heat from the outgoing flows serving to warm up the incoming flow. The liquid phase after cooling is fractionated into a oily rich phase which goes on to a stripping step to recover the contained ethanol residue and an ethanolic phase returned to the extractor. The meal has to be desolventized under vacuum without using steam, which would cause protein heat damage (Salazar-Villanea et al., 2016) and reintroduce water into the solvent.

The totality of these steps is presented in the diagram of Figure 3. The performance of this process was simulated on a laboratory scale by working at approximately $90^{\circ} \mathrm{C}$ with $95 \%$ ethanol in a Nutsche filter on a partially mechanically defatted dehulled rapeseed cake. The device was used to follow the extraction kinetic (evolution of oil concentration in the miscella with the time) and to simulate a multistage extraction. A typical experiment required a Silverson L5M-A high-shear laboratory mixer; an agitated Nutsche filter (POPE Scientific Inc., Saukville, WI) of total capacity $2.78 \mathrm{~L}$, equipped with a stainless steel $20 \mu \mathrm{m}$ mesh; a $5 \mathrm{~L}$ boiler on a scale for the solvent pre-heating equipped with a chamber for the introduction of oil in the solvent prior to extraction and a heating circulator (Huber Kiss 212B) ensuring the temperature regulation of the Nutsche filter. The prepressed rapeseed was dispersed thanks to the high shear disperser (room temperature, $175 \mathrm{~g}$ of press cake in $3.5 \mathrm{~kg}$ of solvent added with $75 \mathrm{~g}$ of oil, $10000 \mathrm{rpm}, 5 \mathrm{~min})$. The liquid was then poured in the preheated filter and $525 \mathrm{~g}$ of new solvent preheated at $110^{\circ} \mathrm{C}$ was added with $75 \mathrm{~g}$ of oil. When the temperature of the mixture was reaching $90^{\circ} \mathrm{C}, 750 \mathrm{~g}$ of miscella was subtracted letting $350 \mathrm{~g}$ of liquid in the filter to simulate the solid ratio found in the heavy phase of cyclonettes (underflow). After removal of this miscella, a new quantity of solvent and oil were directed into the filter for further extractions. The added masses of oil were 75, 12, 4, 2 and $0 \mathrm{~g}$ for the washes 1 , $2,3,4$ and 5 respectively to simulate the decreasing oil concentration of the miscella used in each counterflow steps. The results obtained demonstrated a more efficient extraction of polar lipids and therefore a more thorough extraction of the 


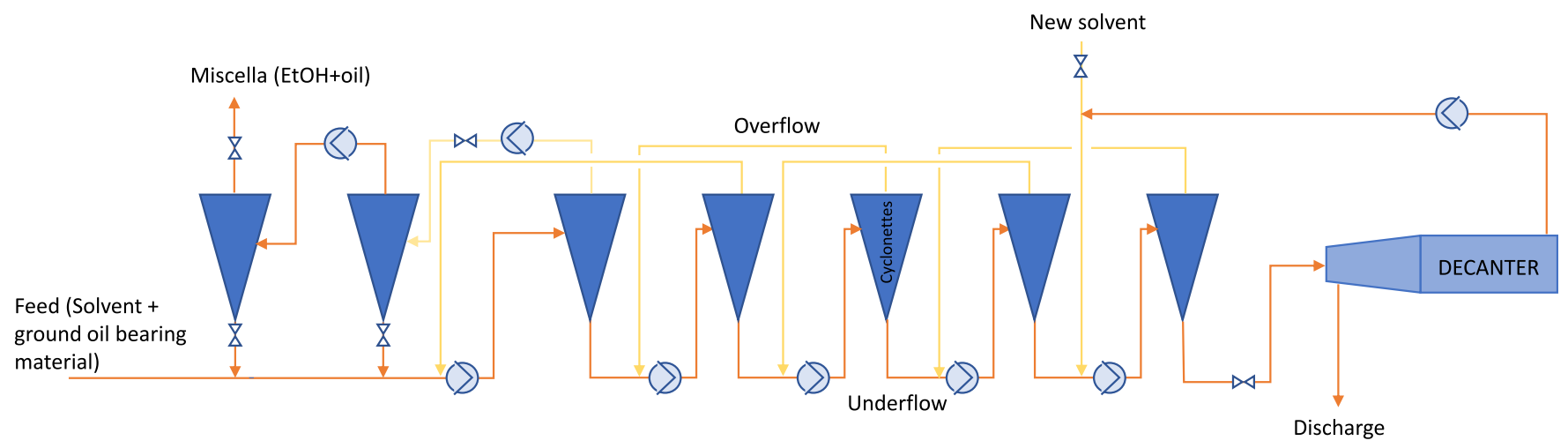

Fig. 2. Flowchart for a counterflow extraction system using 5 steps of solid/liquid separation and using two clarifying stages for the miscella and a centrifuge decanter for dewatering the spent solid (courtesy of Alfa-Laval).

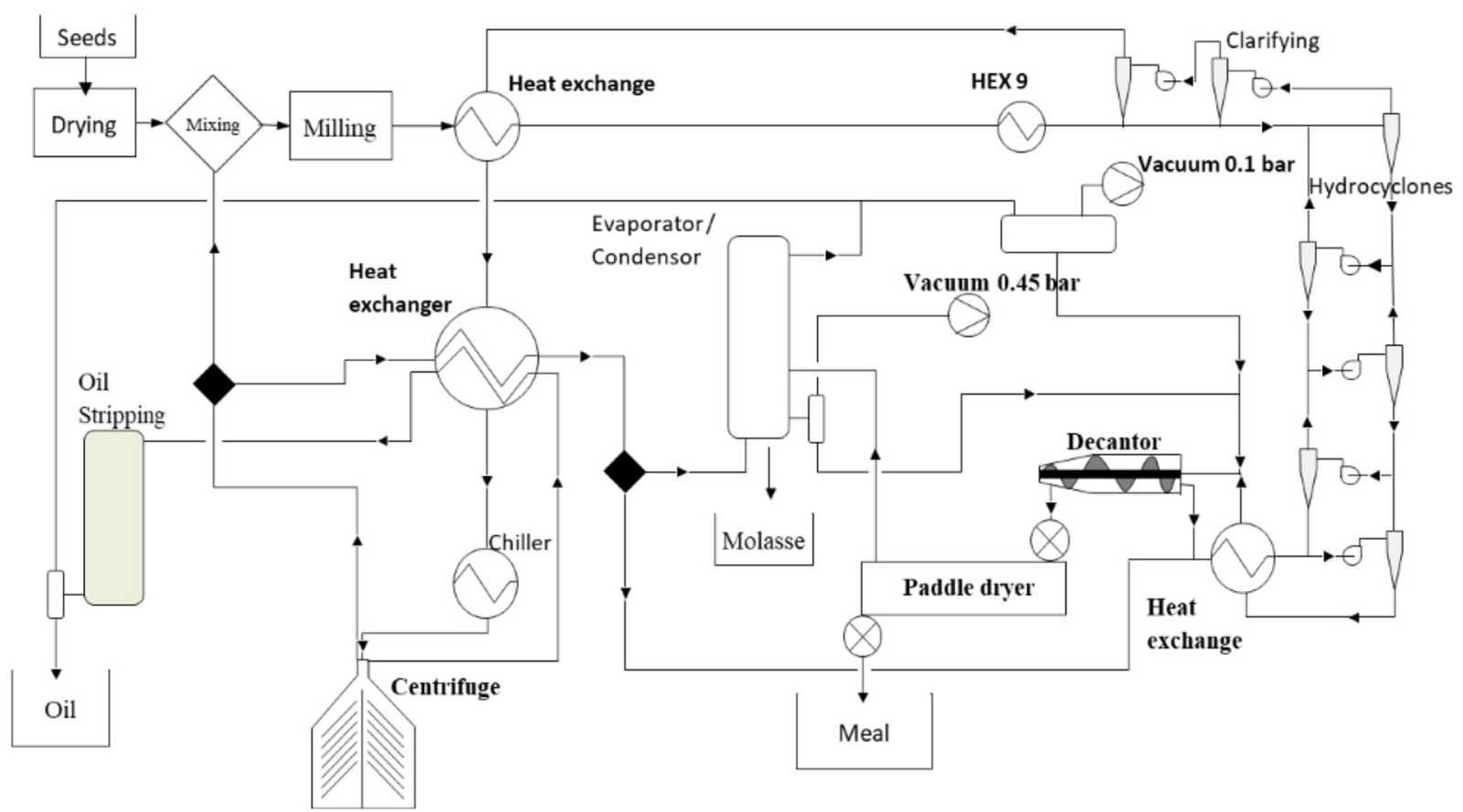

Fig. 3. Flow-chart of the hydrocyclone counterflow extraction system using pressurised ethanol as solvent.

fats than with the hexane in the same conditions. A whitening of the delipidated flour and a reduction in its bitterness were also observed concomitantly with a significant reduction in protein solubility linked to the dehydration effect caused by ethanol (Kalaydzhiev et al., 2020). In the lipid fraction, a partitioning effect was observed during decantation leading to the concentration of triglycerides in the heavy phase while most of the lipids bearing $\mathrm{OH}$ groups were present in the solvent phase as illustrated in Figure 4 (Citeau et al., 2018).

To exploit this effect, it is envisaged to recover the polar lipids after concentration of a fraction of the lean miscella. This concentration would use the heat of the vapors produced by desolventization of the cake. The resulting concentrated miscella would then be fractionated by ultra-filtration on membranes and by using the solubility differentials. The potentially obtainable purified fractions are expected to be rich in phospholipids, tocopherols and sterols, free fatty acids, mono and diglycerides, polyphenolic compounds and finally carbohydrates and other non-lipid compounds.

Using the results of the laboratory study, a computer model was developed (1) to predict the flow of material in a $160 \mathrm{kt} /$ year rapeseed processing unit, and (2) to estimate the process costs. The simulation was performed using an Excel spreadsheet. The solution used to avoid iterative calculation problems was to open the circular calculation loops and use Excel's solver function to find the values allowing to balance the flows taking into account the constraints of the system such as mass balance, saturation concentration of oil/solvent. To estimate the process costs, an approach was used which consisted in evaluating the capital costs based on the cost of the main equipment, using Lang factors to estimate their cost when installed and surrounded by the various utilities. The variable 


\section{Lipids partitionning: lean miscella}

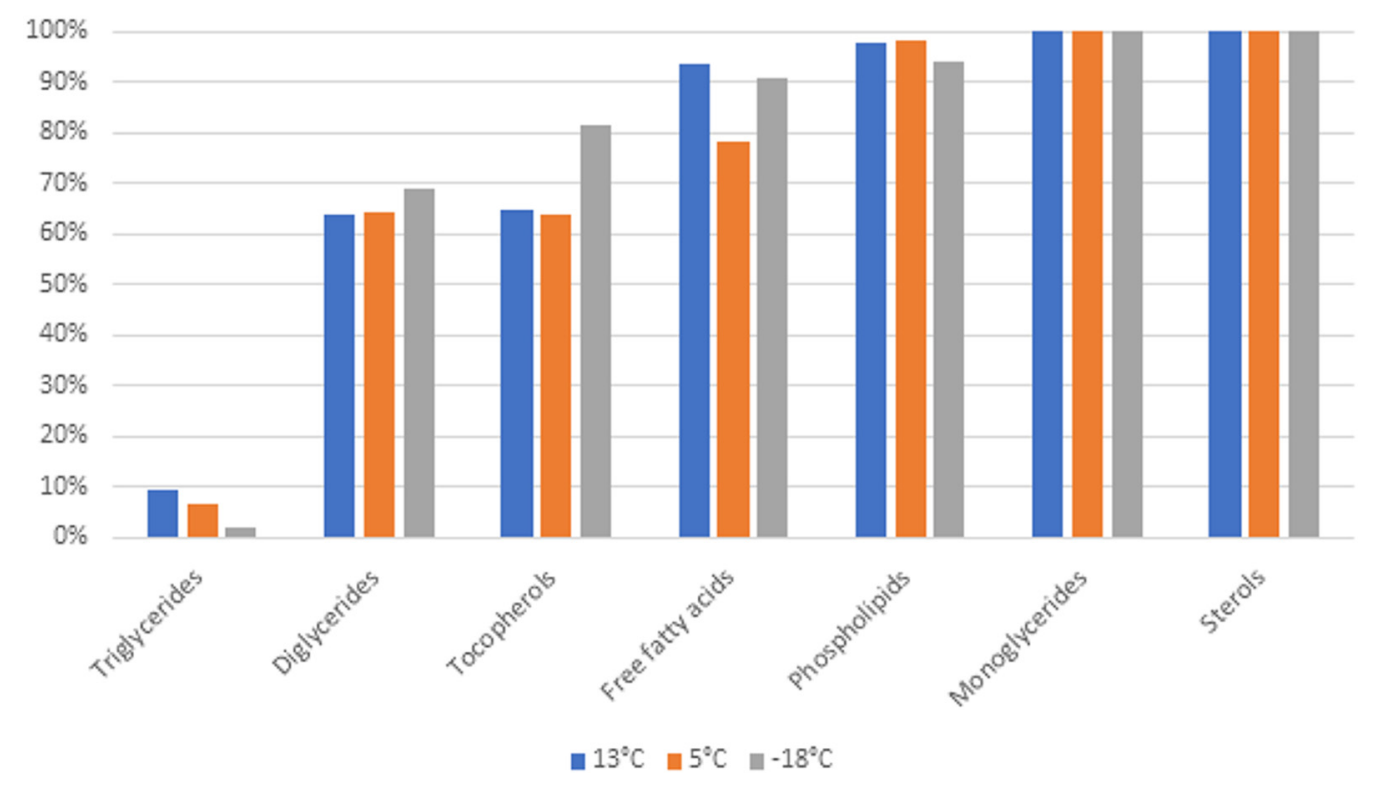

Fig. 4. Proportion of lipid fractions in the "lean miscella" or supernatant fractions resulting from the cooling of the miscella (ethanolic extract of cold pressed rapeseed obtained at $90^{\circ} \mathrm{C}$ ) at 3 decantation temperatures.

Table 1. Estimate of processing costs for a $160 \mathrm{kt} / \mathrm{year}$ rapeseed processing unit using the pressurised ethanol extraction process (Carré et al., 2018).

\begin{tabular}{lrc}
\hline Category & Per year $(€ /$ year $)$ & $\begin{array}{l}\text { Per ton of seed } \\
\text { processed }(€ / \mathrm{t})\end{array}$ \\
\hline Amortization & 2958482 & 16.66 \\
Interest & 697837 & 4.36 \\
Maintenance & 321820 & 2.01 \\
Thermal energy (gas) & 1500000 & 9.38 \\
Electricity & 968800 & 6.06 \\
Workers & 755000 & 4.72 \\
Insurance & 78624 & 0.49 \\
Cash-flow cost & 283089 & 1.77 \\
Other & 320000 & 2.00 \\
Total & 7883652 & 47.44 \\
\hline
\end{tabular}

costs could be estimated on the basis of the energy costs calculated via simulation. The estimated costs are nearly $€ 50 / \mathrm{t}$ of processed seed (Tab. 1) (Carré et al., 2018).

\section{Project to deacidify fragile oils by fractionation in ethanol}

This project ${ }^{3}$ was initiated by OLEAD, faced with a problem regarding the fruit oils sector and more particularly walnut oils. The walnut oils sold on the French market are

\footnotetext{
${ }^{3}$ DEACOL project funded by a grant from the French Ministry of agriculture (CAS-DAR 2015).
}

mainly oils obtained from a mixture of refined oils and virgin oils. Refined oils are usually obtained from second-grade nuts which have gone through various separation processes during which the kernels can be contaminated with phthalates and can sometimes reach significant acidity. To deal with this problem, refining is usually done by the process of physical deacidification during deodorisation (information communicated by the Union Producers of Oils with Taste of France, FRUITOL). The problem is that in order to properly remove phthalates, it is necessary to heat the oils to fairly high temperatures $\left(240{ }^{\circ} \mathrm{C}\right)$, which can cause the formation of unwanted compounds such as the 3MCPD esters (mono-chloro-propane-diol) and glycidyl esters and induce cis/trans isomerization of polyunsaturated fatty acids (Hénon et al., 1999; Hrncirik and van Duijn, 2011). For this reason, OLEAD has proposed using liquid/ liquid extraction in ethanol to lower the acidity of oils and reduce their phthalate concentration.

The process consists in bringing food grade ethanol into contact with the crude oil in a stirred tank and then allowing the mixture to settle to recover an ethanolic supernatant enriched in polar lipids and contaminants (phthalates) and an oily phase containing around $10 \%$ ethanol. With a given walnut oil containing $5.8 \%$ free fatty acids, different concentrations of ethanol and water were tested at a temperature of $27^{\circ} \mathrm{C}$ (room temperature) and several washes with a solvent oil ratio of $1: 2(\mathrm{~m} / \mathrm{m})$ were carried out, thereafter allowing the mixture to settle at $7{ }^{\circ} \mathrm{C}$ (cold-room) overnight. An example of the free fatty acid extraction yields is shown in Figure 5. This graph presents the progressive reduction of the free fatty acids content of a walnut oil when mixed with $2 \mathrm{~kg}$ of solvent (for $1 \mathrm{~kg}$ of oil) for a total of 3-4 repetitions of this mixing. It can be seen from this figure that the lower the water content of ethanol, the better the acid extraction. However, as shown in Figure 6, the lower concentration of water in the solvent results in a greater retention of neutral lipids in the solvent fraction. 


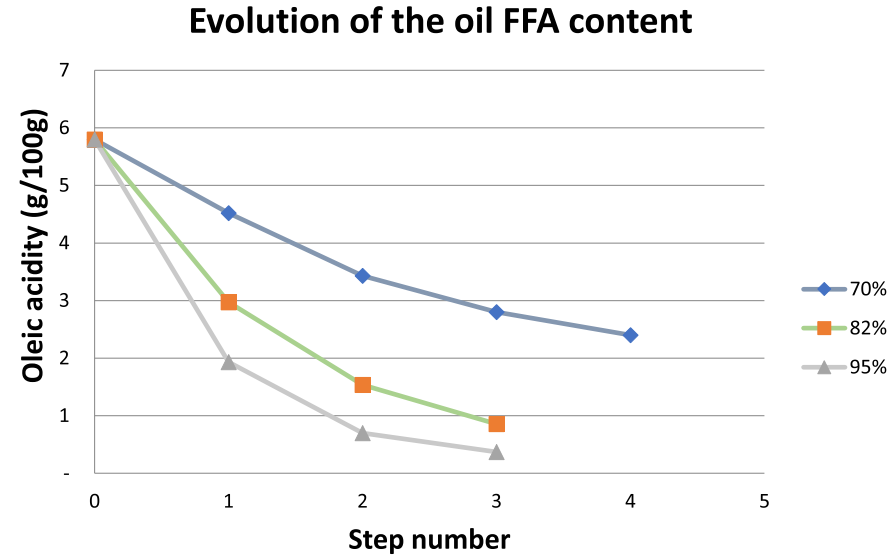

Fig. 5. Effect of ethanol content of the ethanol-water solvent and the number of extraction steps in the free fatty acids extraction at room temperature with 2:1 ration solvent/walnut oil (masses) in liquid/ liquid extraction of acid walnut oil.

\section{Evolution of oil losses}

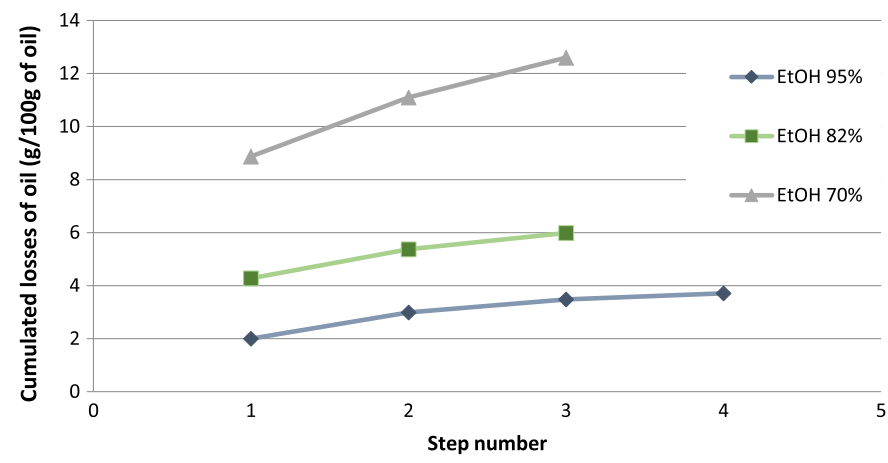

Fig. 6. Evolution of the oil losses as a function of the solvent concentration in ethanol and the number of extraction steps (Solvent/ oil 2:1 ratio, room temperature) in the liquid/liquid extraction of acid walnut oil.

It turns out that the best trade-off is obtained using solvents with between 82.8 and $88.6 \%$ ethanol (Bou Orm et al., 2020).

Regarding the removal of phthalates: when walnut oil was spiked with $116 \mathrm{ppm}$ of butyl-benzyl-phthalate, the extraction yield was $90 \%$ after 3 washes with the oil/solvent in a 2:1 ratio.

Complementary work has been carried out to reduce the volumes of solvent to be used by working at countercurrent in a multistage device. This work was carried out with a batch of oil that is less acidic than in the previous case (3.2\%). The device used presented in Figure 7 comprised 4 stages which allowed the static settling of the mixtures and contacting via static mixers after passing through peristaltic pumps. The residence time in the settlers was of the order of 10 minutes.

This process proves to be effective, making it possible to achieve residual acidities of the order of $0.2 \%$ from a $3.2 \%$ initial oleic acity, but as a result of a relatively short settling time, the losses of neutral oil were not below the desired level: approximately $6 \%$ of oil was lost while according to our previous experiences, losses of a little more than $4 \%$ should have occurred. The reason for these losses is probably the short settling time, which failed to achieve the separation quality of static systems with long duration. This problem could be reduced by using centrifuges, but because this equipment is expensive, it is more realistic for a small-scale unit to opt for larger settling volumes compared to experimental ones (results to be published in an article in preparation).

\section{Use of 2-methyloxolane $\left(\right.$ EcoXtract $\left.^{\circledR}\right)$ as an extraction solvent}

2-methyloxolane is a solvent derived from the recovery of non-food plant biomass (sugar cane bagasse or corn cobs). It is produced by the chemistry of pentoses which undergo initial reducing treatments resulting in the production of furfuraldehyde which then undergoes hydrogenation to 2-methyloxolane (MeOx) (Fig. 8) (Alcantara and de Maria, 2018).

According to the company Pennakem LLC. (Memphis, USA), which produces this solvent, it has a carbon footprint that is significantly lower than that of fossil-carbon-sourced solvents. The main characteristics are a boiling point of $80^{\circ} \mathrm{C}$, a flash point of $-11^{\circ} \mathrm{C}$, a specific gravity at $20^{\circ} \mathrm{C}$ of 0.855 . Compared to hexane, it has a certain miscibility with water. Up to $14 \%$ of the solvent can be dissolved in water and the solvent can contain up to $4.4 \%$ water $\left(20^{\circ} \mathrm{C}\right)$. This partial miscibility with water introduces certain constraints to which we will return later. $\mathrm{MeOx}$ is a very good solvent which can, as a result, act on many polymers. It is therefore necessary to take precautions in its implementation by checking its compatibility with the elastomers with which the seals are made. It also presents a risk of formation of hydroperoxides during storage, which means that it must be stored with antioxidants. Finally, it should be noted that it is very fragrant (ether odour) which in a way improves its detection and avoids the occurrence of handling errors; any insufficiently desolventized product can be detected by its scent.

The affinity of the MeOx solvent was evaluated by AnneGaëlle Sicaire (Sicaire et al., 2015a) using Hansen's solubility parameters. This approach characterises molecules according to 3 parameters:

- $\delta \mathrm{d}$ : Force of dispersion between molecules (London);

- $\delta \mathrm{p}$ : Dipolar intermolecular force;

- $\delta$ h: Hydrogen bond between molecules.

The compatibility of a solvent and a solute can be evaluated by determination of the relative energy difference (RED) between these compounds and this is estimated by calculating their distance in the parameter space defined by the axes $\delta \mathrm{d}, \delta \mathrm{p}$ and $\delta \mathrm{h}$. Table 2 shows the values of the Hansen parameters and average RED of some lipids vis-à-vis hexane and MeOx. The lower the value of RED, the stronger the proximity between the solvent and the solute.

The data in Table 2 show that according to the Hansen parameters, which characterise a method based on the rule "like dissolves like", 2-Methyloxolane is a solvent closer to most lipids than hexane, except for waxes. That means that in theory, $\mathrm{n}$-hexane is not the best solvent for the dissolution of oils and that $\mathrm{MeOX}$ molecules interact better with most of lipids molecules. 


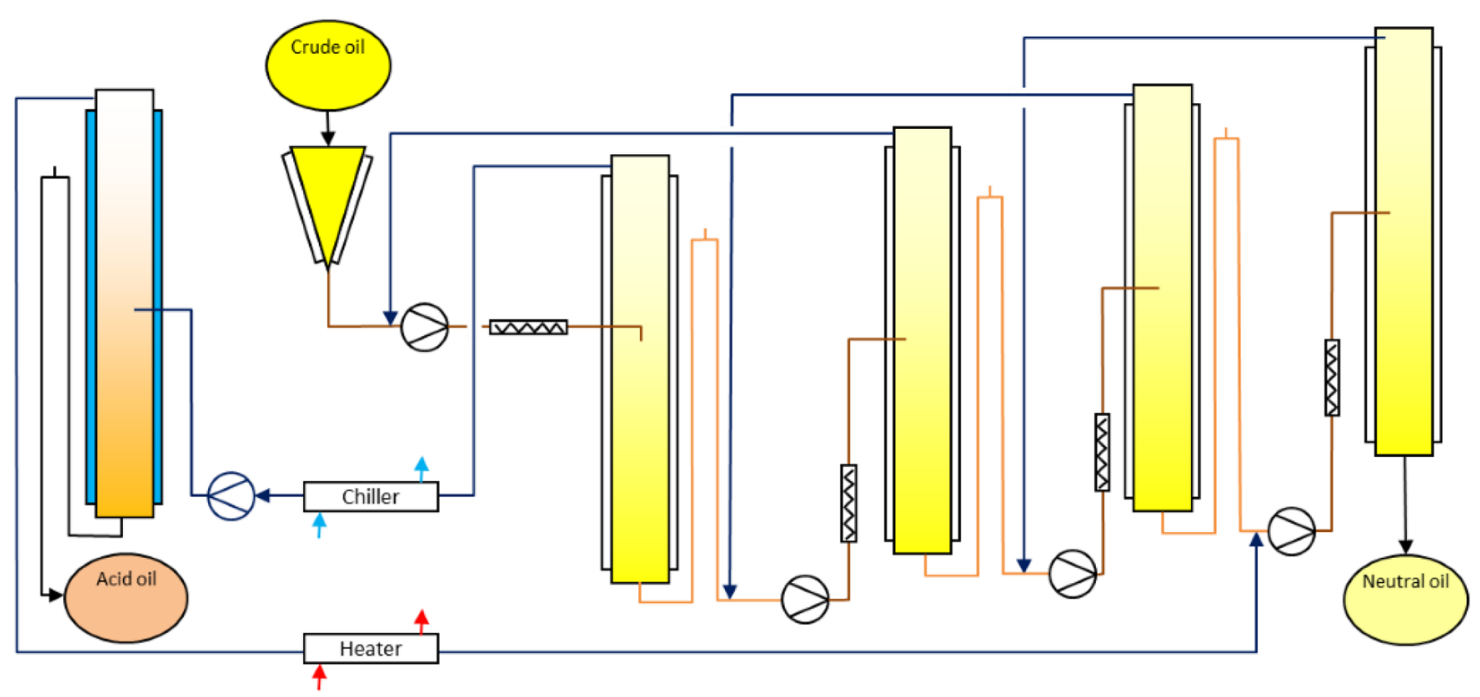

Fig. 7. Diagram of a 4-stage countercurrent extraction device including static decanters and blenders.

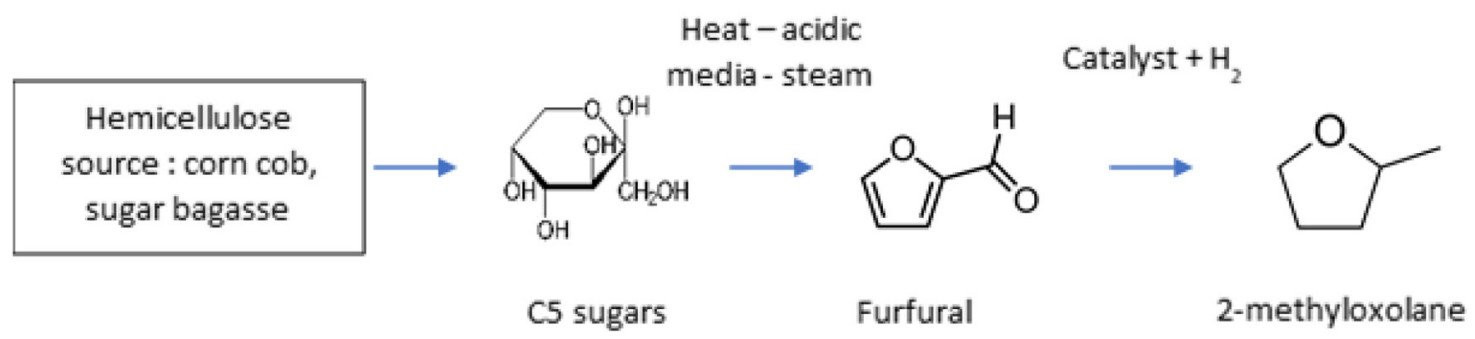

Fig. 8. Production of 2-methyloxolane from hemicellulose-rich biomass (summarized).

Table 2. Comparison of the Hansen parameters and RED values between $\mathrm{n}$-hexane and $\mathrm{MeO}$ and a selection of important lipid classes (Sicaire et al., 2015a).

\begin{tabular}{llcr}
\hline Items & & n-hexane & MeOx \\
\hline \multirow{3}{*}{ Hansen parameters } & $\delta \mathrm{D}$ & 14 & 16.4 \\
$\delta \mathrm{H}$ & $\delta \mathrm{P}$ & 0 & 4.7 \\
& 0 & 4.6 & \\
\hline \multirow{2}{*}{ RED } & Triacylglycerols & 1.09 & 0.90 \\
& Phospholipids & 3.12 & 1.55 \\
& Tocopherols & 1.25 & 0.94 \\
& Sterols & 1.45 & 0.94 \\
& Waxes & 0.81 & 1.15 \\
\hline
\end{tabular}

As part of her thesis work, Anne-Gaëlle Sicaire also compared the degree of affinity of $\mathrm{MeOx}$ for lipids with the one of various solvents such as cyclopentyl-methyl-ether (CPME), dimethyl-carbonate (DMC), isopropanol, ethanol, ethyl-acetate, p-cymene and d-limonene using Cosmos-RS, a powerful software program that simulates the electronic states on the surface of molecules in order to predict their interactions (Sicaire et al., 2015b). The result of these simulations also led to classifying $\mathrm{MeOx}$ as the solvent having the best characteristics for solubilizing common fatty substances. These data have been confirmed by experience, the solvents being compared in a Soxhlet apparatus for measuring the extraction kinetics, yields and oil quality. With the kinetics data obtained by extracting rapeseed prepress cakes and the characterization of the material particle size, Sicaire determined the diffusivity coefficients $\left(\mathrm{D}_{\text {eff }}\right)$ of $\mathrm{MeOx}$ and hexane, obtaining the respective values of $12.2 \times 10^{-12}$ and $3.3 \times 10^{-12} \mathrm{~m}^{2} \mathrm{~s}^{-1}$ - which means that MeOx diffuses almost 4 times faster in the matrix than hexane does. This difference would be explained by a lower hydrophobicity allowing it to more easily cross cell walls rich in cellulose.

In terms of the composition of the oils, Sicaire found a great similarity in composition between the oils obtained from hexane and the oils obtained with $\mathrm{MeOx}$ both in terms of fatty acid profile and in terms of minor compounds (tocopherols, phytosterols). Regarding the colour of the oils it was observed that $\mathrm{MeOx}$ produced darker oils than hexane but this colour difference tended to disappear during refining. Figure 9 shows soybean and rapeseed oils as crude oil, after bleaching and after deodorisation. For soybeans, the oil was obtained by direct extraction, whereas for rapeseed, the crude oil was a mixture of press and extraction oils. Thanks to a method developed in the ITERG analytical lab, the MeOx residues in oils, meal, and co-products can be measured. Table 3 presents the results of a comparison test carried out in our pilot plant 

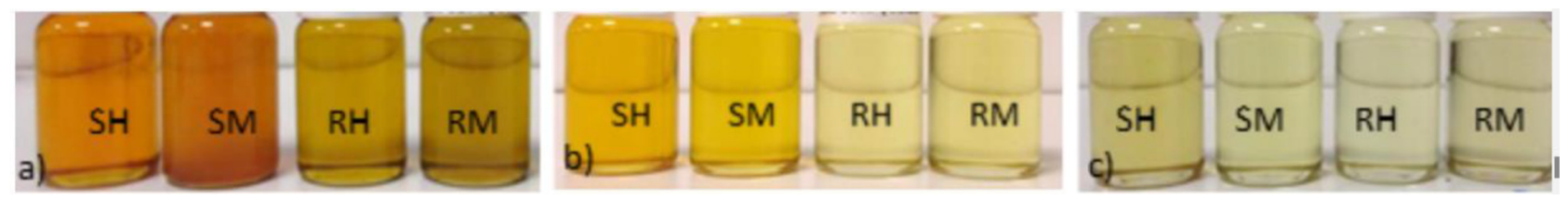

Fig. 9. Oil appearance. a) crude oils, b) alkali neutralised and bleached oils, c) neutralised, bleached deodorised oils. SH: soybean hexane extracted; SM, soy MeOx extracted; RH: rapeseed hexane extracted; RM Rapeseed MeOx extracted.

Table 3. Main characteristics of two refined rapeseed oils obtained from hexane or 2-Methyloxolane extraction (EcoXtract $\left.{ }^{\mathbb{R}}\right)$.

\begin{tabular}{lcc}
\hline Refined rapeseed oil & Hexane & EcoXtract \\
\hline Sterols $(\mathrm{mg} / \mathrm{kg})$ & 7739 & 7397 \\
Tocopherols $(\mathrm{mg} / \mathrm{kg})$ & 620 & 1444 \\
Free fatty acids $(\%)$ & 0.11 & 0.09 \\
Peroxide value $(\mathrm{MeqO} / \mathrm{kg})$ & 0.7 & 0.8 \\
Anisidine value & 6.5 & 5.0 \\
Solvent residues $(\mathrm{mg} / \mathrm{kg})$ & $<1$ & $<1$ \\
\hline
\end{tabular}

where a commercial batch of rapeseed press-cake was divided into two sub-batches of $70 \mathrm{~kg}$ to be extracted with technical hexane or with $\mathrm{MeOx}$. The press cakes were prepared by coldpressing (MBU20 press, Olexa) and contained $22.8 \mathrm{~g}$ of oil for $100 \mathrm{~g}$ of dry matter. The extractions were carried out in a $480 \mathrm{~L}$ Nutsche filter (Guedu-de Dietrich ML500) using $2.5 \mathrm{~kg}$ of solvent for $1 \mathrm{~kg}$ of initial cake at $50{ }^{\circ} \mathrm{C}$ during $15 \mathrm{~min}$. These extractions were made with 3 successive washes in the same conditions. The resulting oils were refined by phosphoric acid conditioning, followed by alkali neutralization, washing to remove the residuals soaps and the caustic soda excess, drying, bleaching with Tonsil $210 \mathrm{FF}$ and deodorisation at $180^{\circ} \mathrm{C}, 2-$ 3 mbar, and steam sparging. The refined oils show similar composition in phytosterols concentration, free fatty acids content (FFA), peroxide value (PV), anisidine value (AV) and solvent residues. For the EcoXtract $^{\circledR}(\mathrm{MeOx})$ sample, a larger concentration of tocopherols was found but in the context of this study, it was not possible to rule out a possible contamination of the sample via the solvent which may have been protected against oxidation with tocopherols.

\section{Conclusion}

Ethanol has three main advantages: of the three solvents, the lowest toxicity for humans ${ }^{4}$; ease of production from renewable products; good acceptance by consumers who consume it in their diet and use it in certain body care products. On the other hand, it is quite disadvantageous as regards miscibility with water and affinity for lipids. This can be turned to advantage if used in a clever way, either via a temperature

4 NOAEL: $1730,23,250 \mathrm{mg} / \mathrm{kg}$ for ethanol, n-hexane, 2Methyloxolane respectively. Sources: for ethanol: ECHA (registration Reach); for n-hexane: European Commission (1996); for MeOx: Rapinel et al. (2020). variation to precipitate lipids after extraction, or by using it to split lipids between neutral lipids and polar lipids. This possibility could be adapted to the production of lipid concentrates of interest, starting from oils intended for uses for which they are not normally valorised as in the case of biofuels. What most certainly penalises ethanol is the energy cost of its implementation, especially when rectification is necessary.

The strong point of hexane, which makes it currently the solvent of choice for crushers, is its low cost of implementation which results, on the one hand from its almost total lack of miscibility with water and, on the other hand, its low latent heat of vaporization; this low latent heat promotes easy recycling and consumes little energy. Its hydrophobicity greatly reduces the presence of undesirable compounds in the oil and makes efficient refining possible. However, it has a serious lack of acceptability linked to its bad reputation as a petroleum product, its toxicity, and the fact that it originates from a nonrenewable resource.

EcoXtract $^{\circledR}$, the trade name for 2-methyloxolane, is a solvent that could be substituted for hexane (with which it shares a high affinity for oils) while being renewable, less toxic, and easier to recycle than ethanol, in particular regarding the proteins fraction. Its main weakness is its cost of implementation because it is more expensive to purchase and because it requires slightly more complex installations to deal with its partial miscibility with water-thus making its recycling more difficult than hexane. Another delicate point regarding this solvent is its acceptability to the general public, who view any novelty with suspicion, and this will require a great deal of caution in the early stages of its development.

Regarding the oils used in cosmetics, ethanol offers interesting possibility for their fractionation, especially for the concentration of active molecules (polar lipids, micronutrients) or the removal of undesirable ones (phthalates). EcoXtract $^{\circledR}$ as extraction solvent has the potential to enable better use of materials sourced from wild species by improving the extraction efficiency and decreasing the volumes taken from the nature.

\section{Conflict of interest}

Studies carried out on 2-methyloxolane by OLEAD (pilot plant studies) were funded by the Pennakem Company when the author was R\&D manager of OLEAD.

\section{References}

Alcantara AR, de Maria PD. 2018. Recent advances on the use of 2methyltetrahydrofuran (2-MeTHF) in biotransformations. Curr Green Chem 5(2): 86-103. 
Beckel AC, Belter PA, Smith AK. 1948. The nondistillation alcohol extraction process for soybean oil. J Am Oil Chem Soc 25(1): $10-11$.

Bou Orm RB, Citeau M, Comitis A, et al. 2020. Walnut oil deacidification by liquid-liquid extraction with ethanol in a single-and multistage crossflow process. OCL 27: 35.

Carré P, Citeau M, Dauguet S. 2018. Hot ethanol extraction: economic feasibility of a new and green process. OCL 25(2): D206.

Choe E, Min DB. 2006. Mechanisms and factors for edible oil oxidation. Compr Rev Food Sci Food Saf 5(4): 169-186.

Citeau M, Slabi SA, Joffre F, Carré P. 2018. Improved rapeseed oil extraction yield and quality via cold separation of ethanol miscella. OCL 25(2): D207.

Cosmos standard. 2020. https://www.cosmos-standard.org/the-cos mos-standard-document?lang=fr (last consult.: September 2020).

ECHA. Ethanol dossier. https://echa.europa.eu/fr/registration-dos sier/-/registered-dossier/16105/7/1 (last consult.: January 2021).

European Commission, Directorate-General Industry. 1996. Opinion of the scientific committee for food on hexane used as an extraction solvent. https://docplayer.net/57348179-Food-scienceand-techniques.html, pp. 35-37.

Ghazani SM, García-Llatas G, Marangoni AG. 2014. Micronutrient content of cold-pressed, hot-pressed, solvent extracted and RBD canola oil: Implications for nutrition and quality. Eur J Lipid Sci Technol 116(4): 380-387.

Hénon G, Kemény Z, Recseg K, Zwobada F, Kovari K. 1999. Deodorization of vegetable oils. Part I: Modelling the geometrical isomerization of polyunsaturated fatty acids. $\mathrm{J} \mathrm{Am} \mathrm{Oil} \mathrm{Chem} \mathrm{Soc}$ 76(1): 73-81.

Hrncirik K, van Duijn G. 2011. An initial study on the formation of 3MCPD esters during oil refining. Eur J Lipid Sci Technol 113(3): 374-379.

Hron Sr, RJ, Koltun SP, Graci Jr, AV. 1982. Biorenewable solvents for vegetable oil extraction. J Am Oil Chem Soc 59(9): 674A-684A.

Johnson L, Lusas EW. 1983. Comparison of alternative solvents for oils extraction. J Am Oil Chem Soc 60(2Part1): 229-242.

Kalaydzhiev H, Ivanova P, Stoyanova M, et al. 2020. Valorization of rapeseed meal: Influence of ethanol antinutrients removal on protein extractability, amino acid composition and fractional profile. Waste Biomass Valoriz 11: 2709-2719.

Kuk MS, Hron Sr RJ. 1998. Cottonseed extraction with a new solvent system: isohexane and alcohol mixtures. $\mathrm{J} \mathrm{Am} \mathrm{Oil} \mathrm{Chem} \mathrm{Soc} 75$ (8): 927-930.
Matthäus B. 2013. Quality parameters for cold pressed edible argan oils. Nat Prod Commun 8(1): 1934578x1300800109.

Matthäus B, Spener F. 2008. What we know and what we should know about virgin oils - A general introduction. Eur J Lipid Sci Technol 110(7): 597-601.

Moreau RA, Powell MJ, Singh V. 2003. Pressurized liquid extraction of polar and nonpolar lipids in corn and oats with hexane, methylene chloride, isopropanol, and ethanol. $\mathrm{J} \mathrm{Am} \mathrm{Oil} \mathrm{Chem} \mathrm{Soc}$ 80(11): 1063-1067.

Prior EM, Vadke VS, Sosulski FW. 1991. Effect of heat treatments on canola press oils. II. Oxidative stability. J Am Oil Chem Soc 68(6): 407.

Raß M, Schein C, Matthäus B. 2008. Virgin sunflower oil. Eur J Lipid Sci Technol 110(7): 618-624.

Rao RK, Krishna MG, Zaheer SH, Arnold LK. 1955. Alcoholic extraction of vegetable oils. I. Solubilities of cottonseed, peanut, sesame, and soybean oils in aqueous ethanol. J Am Oil Chem Soc 32(7): 420-423.

Rapinel V, Claux O, Abert-Vian M, et al. 2020. 2-Methyloxolane (2-MeOx) as Sustainable Lipophilic Solvent to Substitute Hexane for Green Extraction of Natural Products. Properties, Applications, and Perspectives. Molecules 25(15): 3417.

Salazar-Villanea S, Bruininx EM, Gruppen H, et al. 2016. Physical and chemical changes of rapeseed meal proteins during toasting and their effects on in vitro digestibility. J Anim Sci Biotechnol 7 (1): 62 .

Savoire R, Lanoisellé JL, Vorobiev E. 2013. Mechanical continuous oil expression from oilseeds: a review. Food Bioprocess Technol 6 (1): 1-16.

Sicaire AG, Vian MA, Fine F, Carré P, Tostain S, Chemat F. 2015b. Experimental approach versus COSMO-RS assisted solvent screening for predicting the solubility of rapeseed oil. OCL 22 (4): D404.

Sicaire AG, Vian M, Fine F, et al. 2015a. Alternative bio-based solvents for extraction of fat and oils: solubility prediction, global yield, extraction kinetics, chemical composition and cost of manufacturing. Int J Mol Sci 16(4): 8430-8453.

Topkafa M. 2016. Evaluation of chemical properties of cold pressed onion, okra, rosehip, safflower and carrot seed oils: triglyceride, fatty acid and tocol compositions. Anal Methods 8(21): 4220-4225.

Venkitasamy C, Teh HE, Atungulu GG, McHugh TH, Pan Z. 2014. Optimization of mechanical extraction conditions for producing grape seed oil. Trans ASABE 57(6): 1699-1705.

Cite this article as: Carré P. 2021. About solvents used in the preparation of oils for cosmetic products complying with the Cosmos standard. OCL 28: 16. 